\title{
The effect of time of test on muricide, irritability, and open-field activity in the rat
}

\author{
B. MICHAEL THORNE and ANDRE P. BUTEAU \\ Mississippi State University, Mississippi State, Mississippi 39762
}

\begin{abstract}
Muricide, handling characteristics, and open-field activity were tested in either the light portion of a light-dark cycle or the dark portion of a reversed light-dark cycle in male LongEvans hooded rats. Neither mouse killing nor irritability to handling were found to be related to time of test. There was slightly greater horizontal activity in dark-tested rats, who showed little evidence for habituation of exploratory behavior. Light-tested rats showed evidence for habituation of horizontal activity in the open field, along with enhanced rearing in the apparatus.
\end{abstract}

For rodents maintained under light-dark cycles, the stage of the cycle in which testing occurs has been shown to be important for a variety of physiological and/or behavioral measures. For example, the amount of eating and drinking that occurs is much greater during the dark portion of the cycle (e.g., Zucker, 1971). Similarly, locomotor activity is increased in the dark (Richter, 1965). In a study of serotonin synthesis and release in the rat, synthesis occurred mainly in the light and release occurred during the dark portion of the cycle (Hery, Rouer, \& Glowinski, 1972).

Shock-induced fighting and spontaneous home-cage aggression are also affected by lighting conditions (Kane \& Knutson, 1976; Knutson, Hynan, \& Kane, 1976). Knutson et al. found that rats maintained on a light-dark cycle exhibited more shock-induced fighting than did animals studied under a continuous lighting condition. In addition, a periodic trend in fighting was noted in the light-dark animals, with a peak in the dark portion of the cycle.

Kane and Knutson (1976) studied spontaneous home-cage fighting in rats as a function of lighting conditions and found that the highest rates occurred during the dark segment of the cycle. The rate of fighting was low and relatively constant in rats maintained under constant light.

In summary, a number of biologically relevant behaviors in the rat have been shown to be functionally related to the stage of the light-dark cycle in which testing occurs. Because of the strong relationship between hunger and muricide (e.g., Malick, 1975; Paul, Miley, \& Baenninger, 1971; Rager \& Thorne, 1977; Thorne \& Hutton, 1978), it could be predicted that muricide, like hunger and feeding, would be elevated in rats tested during the dark portion of a light-dark cycle.

This research was partially supported by an institutional grant from NSF to Mississippi State University. Send reprint requests to B. Michael Thorne, Drawer PF, Mississippi State, Mississippi 39762.
In a test of this prediction, Thorne and Hutton (1978) compared the muricidal tendencies of LongEvans rats tested near the beginning of either the light portion or the dark portion of a light-dark cycle. The time of the test was not found to be related to muricidal behavior.

Unfortunately, the Thorne and Hutton (1978) study may not be an adequate test of the hypothesis that muricide in the rat is related to the portion of the light-dark cycle in which testing occurs. The most serious flaw was that testing was performed at only one time during either the dark or the light portion of the cycle. The studies by Kane and Knutson (1976) and Knutson et al. (1976) very clearly demonstrated the cyclical nature of spontaneous aggression and shock-induced fighting, respectively. Both measures revealed peaks later into the dark cycle than the point at which testing was performed by Thorne and Hutton.

The purpose of the present study was to provide a more reasonable test of the hypothesis that muricide in the rat is related to the time of testing. Specifically, rats were tested for muricide at one of three different times during the light or the dark portion of a $12: 12$ light-dark cycle. Additionally, reactivity to handling and activity in an open field were assessed in all subjects.

\section{METHOD}

\section{Subjects}

The subjects were 57 adult male Long-Evans hooded rats. All animals were between 3 and 6 months of age at the time of testing. Because of illness, the data from two subjects were deleted. Ad-lib food and water conditions were maintained throughout the study.

The 55 subjects from which data were used were divided into two treatment conditions, with 26 subjects being maintained under a light-dark cycle with light onset at 8:00 a.m. and light offset at 8:00 p.m. The remaining 29 rats were maintained from weaning through testing in a room with a reversed light-dark cycle (i.e., light onset at 8:00 p.m. and light offset at 8:00 a.m.). Within each treatment room, subjects were tested at one of three different times: 8:30 a.m., 12:30 p.m., or $4: 30$ p.m. 
Of the 26 rats tested during the light portion of the lightdark cycle, 9 were tested at 8:30 a.m., 9 at 12:30 p.m., and 8 at $4: 30$ p.m. Of the 29 subjects tested during the dark portion of a reversed light-dark cycle, 10 were tested at $12: 30$ p.m., 10 at $4: 30$ p.m., and 9 at $8: 30$ a.m.

All animals were moved from group housing to single cages 1 week prior to testing. At that time, a dim red light $(25 \mathrm{~W})$ located approximately $60 \mathrm{~cm}$ from the cage rack was turned on in each room. The lights remained on throughout testing and constituted the source of illumination for testing of animals in the room with a reversed light-dark cycle.

\section{Apparatus}

Activity was measured in open-field boxes measuring $76.2 \mathrm{x}$ $76.2 \times 25.4 \mathrm{~cm}$. The boxes were painted flat black, with white lines dividing the floor into 25 equal squares. The top was covered with wire mesh.

\section{Procedure}

On Day 1 of testing, each animal was given a muricidal test at $8: 30$ a.m., 12:30 p.m., or 4:30 p.m. The test was $30 \mathrm{~min}$ in length and consisted of placing an adult albino mouse in to the cage of each rat. Behavioral observation was continual, with latency to kill being recorded when appropriate.

On Days 2-6, testing consisted of a 1-min test of handling characteristics followed by $1 \mathrm{~min}$ of observation in the openfield apparatus. For the test of handling characteristics, a clipboard was placed over the cage of each animal as the animal was removed from the cage rack. The home cage was then carried to a table on which the handling test was administered. The test consisted of rating the animals on a five-item scale used by Thorne, Aaron, and Latham (1973). Each of the five measures was rated on a 4-point scale (0-3), and the ratings of the components were summed to give a daily total. Although reliability tests were not performed in this study, the correlations have been quite high in previous studies in which the same rating scale has been used.

Immediately following the handling test, each rat was placed onto the center square of the open-field box. Horizontal activity was assessed by counting each square the rat entered with all four legs. Rearing consisted of elevation of the forepaws from the floor. All subjects were randomly ordered on each test day to prevent an ordering effect, and the tables and open-field boxes were cleaned after each group had been tested.

\section{RESULTS AND DISCUSSION}

\section{Muricide}

There were no significant differences in mouse killing, and, in fact, only 4 of the 55 rats tested killed. Of the four killers, two were tested in the dark and two in the light.

The results of this study support the previous report by Thorne and Hutton (1978) in which no difference in muricide was found between dark-tested and light-tested rats. In addition, the results are more compelling than in the previous report, since animals were tested at three different time periods within either the light or the dark portion of the cycle. Although it is impossible to prove the null hypothesis, the results of this study plus the Thorne and Hutton report certainly lend a bit of credibility to the idea that muricide in the rat is not a function of time of test.

\section{Handling Characteristics}

Overall, the animals were very docile, with only three earning 5-day scores greater than 6 out of a total possible of 75 . There were no significant differences either within or between lighting conditions.

The lack of greater irritability to handling during the dark portion of a light-dark cycle is in contrast to reports of enhanced shock-induced fighting and spontaneous home-cage aggression in animals tested in the dark (Kane \& Knutson, 1976; Knutson et al., 1976). It is, however, in agreement with the idea that there are several different types of aggression, each with different behavioral characteristics and physiological bases (Moyer, 1968). Thus, it is quite possible that shockinduced fighting and spontaneous home-cage aggression are enhanced during the dark portion of the rats' cycle, whereas predatory and irritable aggression are not.

\section{Horizontal Activity}

Although the differences were not significant, horizontal activity was slightly greater at each testing period for animals tested in the dark when compared with light-tested rats $(8: 30-$ dark: mean $=61.33$, light: mean 57.78; 12:30-dark: mean $=63$, light: mean $=53.78$; $4: 30$-dark: mean $=76.9$, light: mean $=70$ ). In addition, there was slightly greater, although not significantly greater, horizontal activity at the $4: 30$ test period for both dark- and light-tested rats in comparison with subjects tested at either $8: 30$ or $12: 30$.

Figure 1 reveals a much greater decline in horizontal activity over the 5 days of testing for light-tested rats. As a rough measure of habituation, the number of animals whose horizontal activity was less on the last

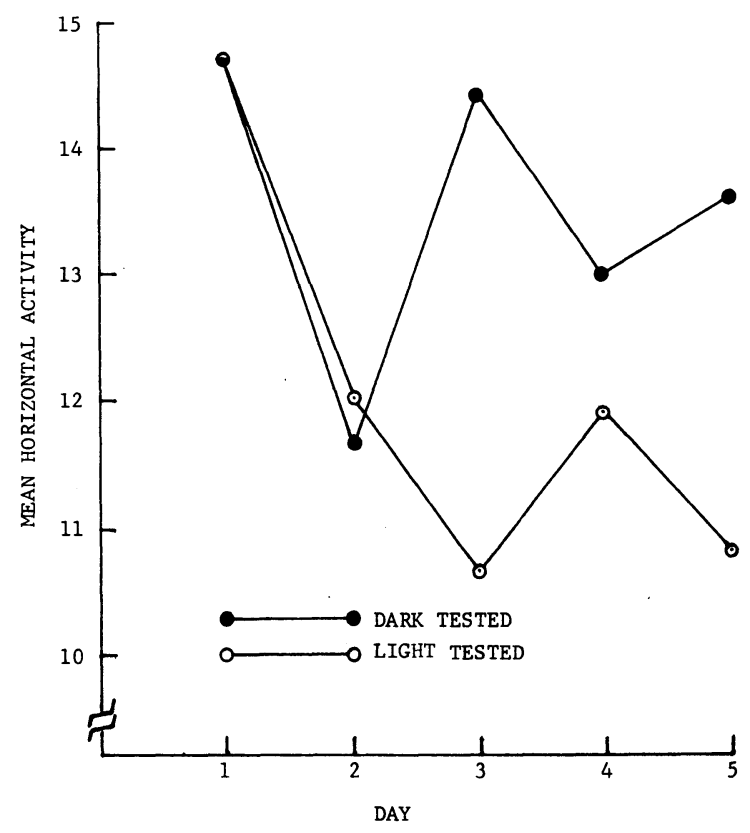

Figure 1. Mean horizontal activity plotted over days. 
day of testing compared with the first was determined, and chi-square tests were performed comparing animals whose scores declined with those whose scores increased. The result was significant for light-tested rats $\left(\chi^{2}=5.54\right.$, $\mathrm{p}<.02$ ), but not for dark-tested animals.

The slightly greater horizontal activity of the darktested animals, seen in the descriptive measures but not in the inferential tests, provides a modicum of support for the greater locomotor activity in the dark reported by Richter (1965). The lack of evidence for habituation in the dark-tested animals provides further support for an enhanced exploratory tendency during the dark portion of the cycle.

\section{Vertical Activity}

An overall comparison of 5-day rearing scores of animals tested in the light vs. those tested in the dark was significant $[t(53)=3.04, p<.01]$. For each test period, the 5-day totals for dark-tested rats were lower than those for light-tested animals, but the only statistically significant difference was for animals tested at $12: 30$ p.m. $[t(17)=2.45, p<.05]$. Time of testing in either the dark or the light was not a factor in the vertical activity scores.

It is difficult to account for the greater rearing activity seen in the light-tested rats. One possible explanation might be that there is an inverse relationship between horizontal activity and rearing. That is, the slightly greater horizontal activity noted in dark-tested subjects was associated with slightly less vertical activity, whereas the opposite result was seen in the light-tested animals.

Unfortunately for this thesis, the correlations between horizontal and vertical activity for dark-tested and light- tested rats were found to be positive. In fact, the relationship for the light-tested animals was significant $(\mathrm{r}=.503, \mathrm{p}<.01)$

\section{REFERENCES}

Hery, F., Rouer, E., \& Glowinski, J. Daily variations of serotonin metabolism in the rat brain. Brain Research, 1972, 43, 445-465.

Kane, N. L., \& KnUtson, J. F. Influence of colony lighting conditions on home-cage spontaneous aggression. Journal of Comparative and Physiological Psychology, 1976, 90, 889-897.

Knutson, J. F., Hynan, M. T., \& Kane, N. L. Influence of home-cage lighting conditions on shock-induced fighting. Journal of Comparative and Physiological Psychology, 1976, $90,877-888$.

MaLick, J. B. Effects of age and food deprivation on the development of muricidal behavior in rats. Physiology \& Behavior, 1975, 14, 171-175.

MOYER, K. E. Kinds of aggression and their physiological basis. Communications in Behavioral Biology, 1968, 2, 65-87.

Paul, L., Miley, W. M., \& Baenninger, R. Mouse killing by rats: Roles of hunger and thirst in its initiation and maintenance. Journal of Comparative and Physiological Psychology, 1971, 76, 242-249.

RAGER, K. B., \& Thorne, B. M. The effects of food deprivation and the length of the test on muricide in rats. Physiology \& Behavior, 1977, 18, 759-762.

RiChte R, C. P. Biological clocks in medicine and psychiatry. Springfield, Ill: Thomas, 1965.

Thorne, B. M., Aaron, M., \& Latham, E. E. Effects of olfactory bulb ablation upon emotionality and muricidal behavior in four rat strains. Journal of Comparative and Physiological Psychology, 1973, 84, 339-344.

Thorne, B. M., \& Hutton, B. The effects of food deprivation and the time of the test on muricide in the Long-Evans rat. Bulletin of the Psychonomic Society, 1978, 6, 307-308.

ZuCKER, I. Light-dark rhythms in rat eating and drinking behavior. Physiology \& Behavior, 1971, 6, 115-126.

(Received for publication January 12, 1981.)

\section{ERRATUM}

Fanselow, M. S. Extinction of contextual fear and preference for signaled shock. Bulletin of the Psychonomic Society, 1980, 16(6), 458-460. Page 459, Column 2, Paragraph 2, Lines 5-8, the sentence should read: The experimental animals spent $60 \%$ of their time on the signaled side, significantly less than the controls, which spent $84 \%$ of their time on the signaled side $[\mathrm{t}(6)=4.76, \mathrm{p}<.01]$. 